\title{
Osteology and relationships of Olorotitan arharensis, a hollow-crested hadrosaurid dinosaur from the latest Cretaceous of Far Eastern Russia
}

\author{
Pascal Godefroit, Yuri L. Bolotsky, and Ivan Y. Bolotsky \\ Acta Palaeontologica Polonica 57 (3), 2012: 527-560 doi: http://dx.doi.org/10.4202/app.2011.0051
}

The holotype of Olorotitan arharensis Godefroit, Bolotsky, and Alifanov 2003, from the Maastrichtian Udurchukan Formation in Kundur, Far Eastern Russia, is the most complete dinosaur discovered in Russia and one of the best preserved lambeosaurines outside western North America. This taxon is diagnosed by these autapomorphies: large helmet-like hollow crest higher than the rest of the skull and extending caudally well beyond the level of the occiput; very high postorbital process of jugal (ratio height of postotbital process / length of jugal =1); rostral portion of the jugal shorter than in other lambeosaurines, with a perfectly straight rostral margin; very asymmetrical maxilla in lateral view, with ventral margin distinctly downturned; very elongated neck composed of 18 cervical vertebrae; tibia as high as the femur; shorter cnemial crest, about one fifth of tibia length. A phylogenetic analysis, based on 118 cranial, dental, and postcranial characters, indicates that Olorotitan is a member of the Corythosaurini clade, and is the sister taxon of Corythosaurus casuarius, Hypacrosaurus stebingeri, and Hypacrosaurus altispinus. The high diversity and mosaic distribution of Maastrichtian hadrosaurid faunas in the Amur-Heilongjiang region are the result of a complex palaeogeographical history and imply that many independent hadrosaurid lineages dispersed readily between western America and eastern Asia at the end of the Cretaceous.

Key words: Olorotitan arharensis, Lambeosaurinae, osteology, phylogeny, Late Cretaceous, Russia.

Pascal Godefroit [Pascal.Godefroit@naturalsciences.be], Royal Belgian Institute of Natural Sciences, rue Vautier 29, 1000 Brussels, Belgium; Yuri L. Bolotsky [dinomus@ ascnet.ru ], Palaeontological Laboratory of the Institute of Geology and Nature Management, Far East Branch, Russian Academy of Sciences, per. Relochny 1, 675000 Blagoveschensk, Russia; Ivan Y. Bolotsky [vargulfr@mail.ru], Research Center for Paleontology and Stratigraphy, Jilin University, Changchun 130061, P.R. China.

This is an open-access article distributed under the terms of the Creative Commons 
Attribution License (for details please see creativecommons.org), which permits unrestricted use, distribution, and reproduction in any medium, provided the original author and source are credited.

Fof Full text $(2.685 .5 \mathrm{kB})$ 